\title{
Marie-Jo THIEL, Marc FEIX (éds.), Le défi de la fraternité. The Challenge of fraternity. Die Herausforderung der Geschwisterkeit
}

Vienne-Zürich, Lit Verlag, coll. « Theology East-West European

Perspectives/Theologie Ost-West Europäische Perspectiven », 2018, 632

p.

Dominique logna-Prat

\section{(2) OpenEdition}

\section{Édition électronique}

URL : https://journals.openedition.org/assr/45227

DOI : $10.4000 /$ assr.45227

ISSN : $1777-5825$

Éditeur

Éditions de l'EHESS

Édition imprimée

Date de publication : 1 décembre 2018

Pagination : $375-376$

ISSN : 0335-5985

\section{Référence électronique}

Dominique logna-Prat, « Marie-Jo thIEL, Marc fEIX (éds.), Le défi de la fraternité. The Challenge of

fraternity. Die Herausforderung der Geschwisterkeit », Archives de sciences sociales des religions [En ligne], 184 | octobre-décembre 2018, mis en ligne le 01 décembre 2018, consulté le 12 janvier 2022 URL : http://journals.openedition.org/assr/45227 ; DOI : https://doi.org/10.4000/assr.45227 


\section{Marie-Jo THIEL, Marc FEIX (éds.), Le défi de la fraternité. The Challenge of fraternity. Die Herausforderung der Geschwisterkeit}

Vienne-Zürich, Lit Verlag, coll. « Theology East-West European

Perspectives/Theologie Ost-West Europäische Perspectiven », 2018, 632

p.

Dominique logna-Prat

\section{RÉFÉRENCE}

Marie-Jo thiEL, Marc feIX (éds.), Le défi de la fraternité. The Challenge of fraternity. Die Herausforderung der Geschwisterkeit, Vienne-Zürich, Lit Verlag, coll. « Theology EastWest European Perspectives/Theologie Ost-West Europäische Perspectiven », 2018, 632 p.

1 Illustré en première de couverture par la sculpture des offrandes de Caïn et Abel au portail central occidental de la cathédrale de Strasbourg, ce collectif consacré au « défi de la fraternité » entend documenter un problème en débat tant dans la dynamique contemporaine des droits de l'homme que dans les évolutions les plus récentes de la doctrine sociale de l'Église catholique. Fruit d'un colloque organisé à Strasbourg, en 2017, à l'initiative de l'Association européenne de théologie catholique (AETC), et publié dans une collection consacrée aux confrontations théologiques Est/Ouest, l'ouvrage est riche de 40 contributions précédées d'une introduction de Marie-Jo Thiel, présidente de l'AETC.

2 Le «défi» (Challenge, Herausforderung) évoqué par le titre est d'abord celui de notre modernité contemporaine au regard des problèmes de solidarité et des manières de faire communauté. «La mondialisation fait de nous des voisins, mais pas des frères et 
sœurs. Le web tisse des connexions mais ne nous fait pas entrer dans une relation fraternelle » (p.5). La fraternité serait-elle donc la réponse au détissage des liens dans la société globale post-moderne? S'appuyant à la fois sur les conceptions éthiques développées par Lévinas, lequel considère la fraternité comme un méta-fait « qui nous constitue de part en part et nous dépasse », et sur les appels du pape François «au nécessaire élargissement de la notion traditionnelle de justice " par mobilisation de la "fraternité comme principe directeur de l'ordre économique ", la démarche proposée dans ce livre est de reprendre le fil historique du rapport du monde chrétien à la notion de fraternité pour proposer à l'éthique des hommes d'aujourd'hui une réponse adéquate au défi du vivre ensemble.

3 À dire vrai, la structure du livre en quatre parties (cadre socio-politique; parcours depuis les sources bibliques jusqu'à la théologie de la fraternité ; expérience chrétienne de la fraternité ; fraternité en pratique) accorde une place majeure à la diversité des pratiques fraternelles et aux questions que ces pratiques ne laissent pas d'adresser aux théologiens. Au fond, le «défi » au cœur du débat est celui de la remise en cause de l'ordre ancien issu de la doctrine sociale de l'Église mise en forme par Léon XIII dans l'encyclique Rerum Novarum. En réponse aux défis du paupérisme et des laissés pour compte de la révolution industrielle, le pape mettait l'accent sur la nécessaire solidarité des chrétiennes et défendait, ce faisant, la capacité de l'Église à travailler de sa puissance immanente la Cité des hommes pour lui permettre d'atteindre au bien commun. La fraternité est ainsi une forme de réécriture de l'ancienne solidarité et une manière d'accommodement de l'Église catholique aux défis du monde actuels. Un pareil accommodement suppose une prise de recul historique qui manque un peu dans ce livre. S'il propose une riche étude de Michel Dujarier (auteur d'un ouvrage de référence sur l'ecclésiologie du Christ-frère) sur la première concrétion chrétienne du concept de fraternité - qui articule les deux notions grecques d'adelphotès (lien vital unissant des frères et des sœurs de sang) et de philadelphia (l'amour fraternel) pour pouvoir penser le grand saut des liens de parentés réels, biologiques, à la parenté spirituelle -, la séquence historique du grand tournant de la fraternité au XIX siècle (spécialement la Révolution de 1848, qui impose la devise républicaine "Liberté, égalité, fraternité ») aurait mérité un meilleur sort dans la mesure où c'est toute la «théologie des réalités terrestres» (G. Thils) qui est alors en jeu - défi auquel l'Église catholique va répondre avec sa doctrine sociale et sa conception de la solidarité. De ce point de vue, un retour aux essais de référence du juriste Marcel David, par ailleurs fondateur des Instituts du travail à Strasbourg après la Seconde Guerre mondiale, sur l'histoire la fraternité aurait été bienvenu. Enfin, une étude du défi posé par les " petites fraternités électives » qui se composent et se recomposent aux marges de l'appareil ecclésial n'aurait pas été mal venue pour mettre les appels du pape François en perspective. Par le recours à la fraternité, l'Église catholique défie certes le monde; mais les pratiques fraternelles de base la mettent elle-même au défi de s'adapter aux évolutions du monde chrétien. 